\title{
The species and chromosomal distribution of the centromeric-satellite I sequence from sheep in the tribe Caprini and other Bovidae
}

\author{
R. Chaves, ${ }^{a, b}$ H. Guedes-Pinto ${ }^{b}$ J.S. Heslop-Harrison ${ }^{a}$ and T. Schwarzacher ${ }^{a}$ \\ a Department of Biology, University of Leicester, Leicester (UK); \\ b Department of Genetics and Biotechnology, ICETA - UTAD, University of Trás-os-Montes and Alto Douro, \\ Vila Real (Portugal) \\ Dedicated to Professor Dr. Ulrich Wolf on the occasion of his retirement.
}

\begin{abstract}
.
The evolution of chromosomes in species in the family Bovidae includes fusion and fission of chromosome arms (giving different numbers of acrocentric and metacentric chromosomes with a relatively conserved total number of arms) and evolution in both DNA sequence and copy number of the pericentromeric - -satellite I repetitive DNA sequence. Here, a probe representing the sheep - -satellite I sequence was isolated and hybridized to genomic DNA digests and metaphase chromosomes from various Bovidae species. The probe was highly homologous to the centromeric sequence in all species in the tribe Caprini, including sheep (Ovis aries), goat ( $\mathrm{Ca}$ pra hircus) and the aoudad or Barbary sheep (Amnotragus lervia), but showed no detectable hybridization to the - -satellite I
\end{abstract}

\section{Introduction}

The family Bovidae in the order Artiodactyla (even-toed ungulates) includes some 124 species in 45 genera (Vaughan, 1986). Many of these are of economic importance (including cattle, sheep and goats), and some significant landraces and species are endangered or threatened with extinction. A taxonomic division of the Bovidae has been made by Gentry (1992) based on morphological and karyotypic criteria, and this classification, recognizing tribes (rather than subfamilies), is used here (Table 1). However, there are areas where phylogenetic relationships are unclear, and molecular data, including mitochondrial and ribosomal DNA sequences (Gatesby, 1992; Al- lard et al., 1992), is increasing the resolution of the phylogeny. Data from examining the distribution of satellite DNA se- quences (Modi et al., 1996; Jobse et al., 1995) has resolved fur- ther ambiguities within the Tribe Bovini. The number of auto- somal chromosome arms in the karyotypes of sequence present in the tribe Bovini and at most very weak to species in the tribes Hippotragini, Alcelaphini or Aepycerotini. The sex chromosomes of sheep, goat and aoudad did not contain detectable - -satellite I sequence; in sheep, one of the three metacentric autosomal chromosomes does not carry the sequence, while in aoudad, it is essentially absent in three large autosomal pairs as well as the large metacentric chromosome pair. The satellite probes can be used as robust chromosome and karyotype markers of evolution among tribes and increase the resolution of the evolutionary tree at the base of the Artiodactyla.

the Bovidae is almost constant with 56 to 58 arms, plus the $\mathrm{X}$ and Y chromo- somes (Wurster and Benirschke, 1968). Because of the varia- tion in the number of biarmed chromosomes, the number of autosomes varies from 28 to 58 (Bunch, 1978, Bunch et al.,

1976). Differences in number of monobrachial and biarmed chromosomes have been particularly evident within the tribe Caprini (Table 1), which contains ten genera (Franklin, 1997) including sheep (Ovis), goats (Capra), aoudads (Amnotragus), and bharals (Pseudois). The thars (Hemitragus) maintain behavioural and morphological similarities to the aoudad and may be ancestral to sheep and goats (Bunch, 1978). Now, evolution of Ovis, Amnotragus and Pseudois karyotypes from a suggested ancestral karyotype of $2 \mathrm{n}=60$ is postulated to involve a series of Robertsonian translocations (also referred to as 

Robertsonian or centric fusions with loss of a chromosome fragment) resulting in one $(2 \mathrm{n}=58)$, two $(2 \mathrm{n}=56)$, three $(2 \mathrm{n}=$ $54)$ or four $(2 n=52)$ pairs of biarmed chromosomes (Bunch et al., 1976; Bunch, 1978). Earlier suggestions of evolution of modern karyotypes by fission from a largely metacentric karyotype are largely discounted.

A substantial proportion of the higher eukaryote genome consists of constitutive heterochromatin. This genomic fraction includes, among other repetitive sequences, satellite DNAs (very highly repetitive, tandemly repeated sequences) that usually reside in the pericentric regions of chromosomes (D'Aiuto et al., 1997). Sequence analysis of these repeats suggests that the sequences are rapidly evolving, and hence they are valuable as evolutionary markers (Saffery et al., 1999). The - -satellite I sequence has been studied in goat and sheep for many years (Buckland, 1983), and bovine and caprine sequences have been compared (Buckland, 1985). In an important paper, Modi et al. (1996) examined the distribution of six satellite sequences by Southern and in situ hybridization in the Artiodactyls. These authors were able to suggest age of the repeats, and the results supported the monophyly of the subfamily Bovinae, although any interrelationships among the other tribes of bovids could not be resolved. Cytogenetically, they showed a reduction in diploid chromosome numbers through centric fusion in derived karyotypes was accompanied by a loss of centromeric satellite DNA. Burkin et al. (1996) demonstrated that the centromeres of the sheep biarmed chromosomes (1, 2 and 3) are different with respect to DNA sheep satellite I amount and organization. D'Aiuto et al. (1997), analysed satellite I DNA by in situ hybridization in sheep, finding that the intensity of labeling was clearly different on the labeled sheep chromosomes, suggesting either a different number of copies of the sequence in different chromosomes or the presence of chromosome-specific repeat families.

Here, we aimed to increase the resolution of the analysis of satellite I sequences of tribes in the Bovidae that are diverged from the Bovini. In particular, we aimed to compare the distribution of the sequences in major genera within the tribe Caprini (Capra, Amnotragus and Ovis). We also compared these genera with species from other tribes: the Bovini (including cattle, Bos taurus), thought to have diverged from the Caprini early in evolution, the Aepycerotini (impala), Hippotragini (sable antelope) and Alcelaphini (gnu).

\section{Materials and methods}

The species and breeds analysed are shown in Table 1. Genomic DNA was isolated from peripheral blood by standard methods. Chromosome prep- arations were made from shortterm cultures of lymphocytes; where only small amounts of blood were available, cultures were made.

To isolate the centromeric sheep satellite I sequence, genomic DNA from sheep was digested with BamHI and separated by gel electrophoresis. A prominent fragment $1.7 \mathrm{~kb}$ long (see arrow, Fig. 1) was cut from the gel and cloned in the BamHI site of pUC18. One clone, named pOaKB9 was selected for further analysis. The nucleotide sequences were determined in both strands by an automatic sequencer. DNA sequences were analysed using BLASTN searches of the Genbank and EMBL databases.

For Southern hybridization, genomic DNA from each species was digested with EcoRI and BamHI, size separated in $0.8 \%$ agarose gels in $1 \times$ TBE buffer for $16-18 \mathrm{~h}$ and transferred to Hybond N+ (Amersham) mem- branes. The membrane was probed with pOaKB9 using $100 \mathrm{ng}$ of probe and the ECL-direct (Amersham) hybridization system.

Chromosome preparations and in situ hybridization followed standard techniques (Schwarzacher and HeslopHarrison, 2000). pOaKB9 was labeled with biotin-16-dUTP and digoxigenin-11-dUTP (Roche), and hybridization, using $100 \mathrm{ng}$ of probe, was performed at $37^{\circ} \mathrm{C}$ in $2 \times \mathrm{SSC}, 50 \%(\mathrm{v} / \mathrm{v})$ formamide and $10 \%$ dextran sulphate, in a volume of 15 Ill for each slide. Post- hybridization washing was carried out at $42{ }^{\circ} \mathrm{C}$ in 2 $\times \mathrm{SSC}, 50 \%$ formamide followed by two washes in $0.1 \times \mathrm{SSC}$ at $60^{\circ}$ C. Biotin label was detected by Cy3-conjugated streptavidin or an avidin-DCS conjugate, while digoxigenin was detected with anti-digoxigenin FITC. Chromosomes were counter- stained with DAPI. Micrographs were taken on Fujicolor 400 print film, dig- itized to PhotoCD and printed from Adobe Photoshop after overlaying images and contrast adjustment using only functions affecting the whole image equally.

\section{Results}

\section{The centromeric sheep satellite I sequence}

A BamHI fragment of approximately $1,700 \mathrm{bp}$, corresponding to a prominent band in an ethidium bromide-stained gel (arrow, Fig. 1), was cloned from genomic DNA of sheep. One clone, pOaKB9, was sequenced and a search in the nucleic acid database identified it as being a member of the sheep - -satellite I DNA family as reported by Reisner and Bucholtz (1983) and Buckland (1983).

\section{Southern Analysis}

The probe pOaKB9 was hybridized to Southern blots of restriction digested genomic DNA from three species (Table 1; Fig. 1). A ladder hybridization pattern characteristic of satellite sequences was observed in the Caprini species goat and sheep, but no hybridization was detected in cattle (Bovini).

\section{In situ hybridization}

Figure 2 shows hybridization of the sheep - -satellite I probe pOaKB9 to chromosome preparations from sheep, goat and aoudad (all tribe Caprini). No hybridization was detected to chromosomes of cattle (as expected from the Southern hybridization result, Fig. 1), and minimal hybridization in impala, sable antelope and gnu, all in tribes outside the Caprini. Where hybridization was detected, all acrocentric autosomal chromosomes were labeled at their centromeres in sheep and goats. In 
sheep, the biarmed chromosomes 2 and 3 (identified by prior G-banding, not shown) were labeled, but the biarmed chromosome 1 (arrowed in Fig. 2c) and the sex chromosomes (arrowhead for X) did not show hybridization. In goat (Fig. 2d-f), the pOaKB9 sequence labeled the centromeric region of all 29 pairs of acrocentric autosomes, but not the sex chromosomes (arrowheads in Fig. 2f). The general intensity of the labeled chromosomes was higher compared to the intensity displayed on sheep and aoudad chromosomes. To compare the strength of hybridization of the probe in the Caprini, we mixed fixations of sheep and goat chromosomes. After hybridization, more intense signals were seen on the goat metaphases, suggesting that there was a higher copy number of the sequence (or perhaps that the particular variant of the satellite present in the clone was more abundant) in goat than sheep. In the auodad, the sex chromosomes and chromosome 1 are biarmed (identified by G-banding); these chromosomes showed almost no hybridization of the satellite I probe (Fig. 2g-i; Y chromosome not shown). Two pairs of large acrocentric chromosomes also showed almost no hybridization of the probe.

\section{Discussion}

The analysis of satellite DNA sequence, organization and chromosome distribution, in conjunction with karyotype analysis, is a valuable tool to measure species relationships while also elucidating important aspects of both genome and repetitive sequence evolution. As discussed by Modi et al. (1996) and Jobse et al. (1995), satellite DNA sequences are useful markers for speciation and genome divergence. We used an - -satellite I probe isolated from sheep (pOaKB9), hybridizing to the centromeric regions of sheep autosomal acrocentric chromosomes, as a marker for genome evolution in five tribes of the family Bovidae (Table 1). The tribes Caprini and Bovini are among the most distantly related pair of tribes within the Bovidae (Buckland, 1985). We found no hybridization of pOaKB9 to bovine DNA or chromosomes, consistent with the results of Buckland (1985); database analysis shows that sequenced bovine - -satellite I DNA sequences show only $70 \%$ homology to the sheep sequence, less than the stringency of hybridization we used.

In sheep, Iannuzzi and DiMeo (1995) reported loss of a pericentric G-positive band on chromosome $2 \mathrm{q}$ in comparison with the homologous chromosome arm in cattle and goats where it is not involved in fusion, suggesting the loss of constitutive heterochromatin during formation of biarmed chromosomes, and the results here show that this involves the --satellite I. The equivalent sequence may also be lost during formation of the 1;29 Robertsonian translocation in cattle breeds (Chaves et al., 2000). The different and non-homologous nature of the satellite sequences in Bovini and Caprini leaves open the possibility that sequence amplification and dispersion mechanisms may differ between groups: - -X satellite DNA was the only alphoid DNA probe localized to the centromeric regions of different and non-homologous chromosomes in each great ape species (Archidiacono et al., 1995). Repetitive DNA at non-centromeric, interstitial sites of mammalian $\mathrm{X}$ chromosomes is largely species-specific, but Lee et al. (1999) used gamma-X sequence hybridization to show that great apes and old world monkeys have homologous repetitive sequences at the centromeric regions of the $\mathrm{X}$ chromosomes indicative of synteny conservation (orthologous evolution).

In the Caprini (Table 1), the sheep satellite I sequence hybridized strongly to all centromeric regions of autosomal acrocentric chromosomes (Fig. 2) except for three large pairs in aoudad. The biarmed chromosomes are likely to have arisen sequentially by fusion of monobrachic chromosome arms: the fusion to form chromosome 1 is regarded as the most ancient, and the chromosome 3 and then chromosome 2 fusions are more recent (Bunch et al., 1976). In sheep, we see substantial satellite I hybridization signal on biarmed chromosomes 2 and 3 (Fig. 1), although previous authors probing sheep satellite I to sheep chromosomes found very little or no signal on chromosomes 2 and 3: Burkin et al. (1996) used DNA from sheep-hamster cell fusion hybrids, while D'Aiuto et al. (1997) used in situ hybridization. The results suggest a difference between the Portuguese landrace we analysed, Churra da Terra Quente, and the Sarda landrace analysed by D'Aiuto et al. (1997). If loss of the satellite sequences is a gradual process, rather than happening at the time of the fusion (the Robertsonian translocation), then the lack of satellite on chromosome 1 is consistent with its older origin. The karyotype of aoudad has only the first, chromosome 1 , fusion, and we did not detect hybridization of the sheep satellite I sequence (Fig. 2d); however, it is notable that some larger acrocentric chromosomes are missing the satellite sequence, perhaps indicating that its loss is independent of or may precede chromosome fusion in evolutionary time. The differences detected between both species and races may be useful in defining relationships between breeds and for conservation programmes aiming to include the maximum level of diversity.

Using morphological and geographical criteria, breed origin and relationships are very difficult to ascertain because of long distance movement of animals and interbreeding (Maijala, 1997). There are a number of theories about the origin of domestic sheep, including the suggestion that they evolved from the aoudad (Burditt, 1996). Although genetic mapping demonstrates conserved synteny between chromosome arms, biarmed chromosomes may involve fusion of different monobranchic chromosomes: Gallagher and Womack (1992) and

Gallagher et al. (1994) examined 76 biarmed chromosomes from various Pecorans and concluded that the biarmed chromosomes were often independently derived by centric fusion in the different species. The $\operatorname{Rob}(1 ; 29)$ chromosome is carried in many cattle breeds along with the 1 and 29 chromosomes (see, e.g. Rangel-Figueiredo and Iannuzzi, 1991). The wide distribution of heterozygous carriers in many breeds and the extensive chromosomal polymorphisms suggest that at least the 1;29 Robertsonian translocation has occurred multiple times in the evolution of cattle (Chaves et al., 2000).

Increasing evidence shows that there is no "molecular clock" for repetitive DNA sequence evolution. The results here, taken with others, suggest that bursts of evolution and/or homogenization of repetitive sequences may have occurred within ancestral genomes, followed by periods of stability in the new species. Genes and single copy sequences may not be the optimum markers for evolution: allelic differences within species may be no larger than differences between species, and many genes are similar between cattle, goat and sheep (e.g. Lopez-Corrales et al., 1999). However, it is likely that genome rearrangements associated with chromosome remodelling during evolution both lead to reproductive isolation and are responsible for the modulation of gene expression. Wolf (1995, 
1997) has discussed the relationship of mutation and epigenetic alterations of gene expression with respect to phenotypic heterogeneity, and it is worth speculating that such modulations of gene expression, perhaps driven by chromosomal and repetitive sequence rearrangements, are instrumental in the processes of speciation.

\section{Acknowledgement}

We thank the Lisbon Zoo and particularly Professor Pereira da Silva for assistance and for the supply of blood samples from the wild species.

\section{References}

Allard MW, Miyamoto MM, Jarecki L, Kraus F, Ten- nant MR: DNA systematics and evolution of the artiodactyl family Bovidae. Proc natl Acad Sci, USA 89:3972-3976 (1992).

Archidiacono N, Antonacci R, Marzella R, Finelli P, Lonoce A, Rocchi M: Comparative mapping of human alphoid sequences in great apes using fluorescence in-situ hybridization. Genomics 25:477484 (1995).

Buckland RA: Comparative structure and evolution of goat and sheep satellite I DNAs. Nucl Acids Res 11:1349-1360 (1983).

Buckland RA: Sequence and evolution of related bo- vine and caprine satellite DNAs. Identification of a short DNA sequence potentially involved in satel- lite DNA amplification. J molec Biol 186:25-30 (1985).

Bunch TD: Fundamental karyotype in domestic and wild species of sheep. J Hered 69:77-80 (1978)

Bunch TD, Foote WC, Spillet JJ: Translocations of acrocentric chromosomes and their implications in the evolution of sheep. Cytogenet Cell Genet 17: 122-136 (1976).

Burditt L: Breeds of livestock. http://www.ansi-okstate.edu/BREEDS/SHEEP/Sheep-w.htm (1996).

Burkin DJ, Broad TE, Jones C: The chromosomal dis- tribution and organization of sheep satellite I and II centromeric DNA using characterized sheep- hamster somatic cell hybrids. Chrom Res 4:49-55 (1996).

Chaves R, Heslop-Harrison JS, Henrique Guedes-Pin- to H: Centromeric heterochromatin in the cattle $\operatorname{rob}(1 ; 29)$ translocation: - -satellite I sequences, in situ MspI digestion patterns, chromomycin stain- ing and C-bands. Chrom Res (in press 2000).

D'Aiuto L, Barsanti P, Mauro S, Cserpan I, Lavane C, Ciccarese S: Physical relationship between satellite I and II DNA in centromeric regions of sheep chromosomes. Chrom Res 5:375-381 (1997).

Franklin IR: Systematics and phylogeny of the sheep, in Piper L, Ruvinsky A (eds): The Genetics of Sheep, pp 5-11 (CAB International, New York 1997).

Galagher DS Jr, Derr JN, Womack J: Chromosome conservation among the advanced Pecorans and determination of the primitive Bovid karyotype. J Heredity 85:204-210 (1994).

Gallagher DS, Womack JE: Chromosome conservation in the Bovidae. J Heredity 83:287-298 (1992).

Gatesby J, Yelon D, DeSalle R, Vrba ES: Phylogeny of the Bovidae (Artiodactyla, Mammalia), based on mitochondrial ribosomal DNA sequences. Mol Biol Evol 9:433-446 (1992).

Gentry AW: The subfamilies and tribes of the family Bovidae. Mammal Rev 22:1-32 (1992).

Iannuzzi L, DiMeo GP: Chromosomal evolution in bovids: a comparison of cattle, sheep and goat G- and R-banded chromosomes and cytogenetic di- vergences among cattle, goat and river buffalo sex chromosomes. Chrom Res 3:291-299 (1995).

Jobse C, Buntjer JB, Haagsma N, Breukelman HJ, Beintema JJ, Lenstra JA: Evolution and recombi- nation of Bovine DNA repeats. J molec Evol 41: 277-283 (1995).

Lee C, Stanyon R, Lin C-C, Ferguson-Smith MA: Con- servation of human gamma-X centromeric satellite DNA among primates with an autosomal localiza- tion in certain Old World monkeys. Chrom Res 7:43-47 (1999).

Lopez-Corrales NL, Sonstegard TS, Smith TPL: Physi- cal mapping of the bovine, caprine and ovine homologues of the paired box gene PAX8. Cyto- genet Cell Genet 84:179-181 (1999).

Maijala K: Genetic aspects of domestication, common breeds and their origin, in Piper L, Ruvinsky A (eds): The Genetics of Sheep, pp 25-27 (CAB International, New York 1997)

Modi WS, Gallagher DS, Womack JE: Evolutionary histories of highly repeated DNA families among the Artiodactyla (Mammalia). J molec Evol 42: 337-349 (1996).

Rangel-Figueiredo T, Iannuzzi L: A cattle breed close to 58 diploid number due to high frequency of $\operatorname{rob}(1 ; 29)$. Hereditas 115:7378 (1991).

Reisner AH, Bucholtz CA: Apparent relatedness of the main component of ovine 1.714 satellite DNA to bovine 1.715 satellite DNA. EMBO J 2:1145-1149 (1983).

Saffery R, Earle E, Irvine DV, Kalitsis P, Choo KHA: Conservation of centromere proteins in verte- brates. Chrom Res 7:261-265 (1999).

Schwarzacher T, Heslop-Harrison JS: Practical in situ hybridisation, pp 203 (Bios, Oxford 2000)

Vaughan TA: Mammalogy, p 210 (CBS College, New York 1986).

Wolf U: Identical mutations and phenotypic variation. Hum Genet 100:305-321

(1997).

Wolf U: The genetic contribution to the phenotype. Hum Genet 95:127-148 65

(1995)

Wurster DH, Benirschke K: Chromosome studies in the superfamily Bovoidea. Chromosoma 25:152-171 (1968). 


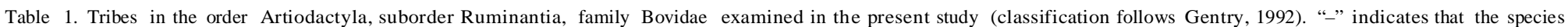

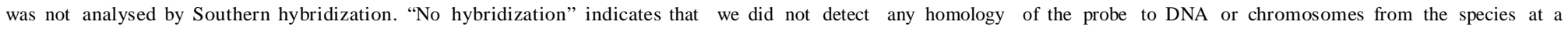
hybridization stringency of $80-85 \%$.

\begin{tabular}{llllll}
\hline Tribe & Species & Common name & $\begin{array}{l}\text { Chromosome } \\
\text { number }\end{array}$ & $\begin{array}{l}\text { Southern hybridization } \\
\text { (Fig. 1) }\end{array}$ & $\begin{array}{l}\text { In situ hybridization } \\
\text { (Fig. 2; parts in brackets) }\end{array}$ \\
\hline Bovini & Bos taurus & Domestic cow & 60 & No hybridization & No hybridization \\
Hippotragini & Hippotragus niger & Sable antelope & 58 & - & Minimal hybridization \\
Alcelaphini & Connochaetes taurinus & Gnu or Boi cavalo & 58 & - & Minimal hybridization \\
Caprini & Capra hincus & Domestic goat & 60 & Ladder & Centromeres (a-c) \\
& Amnotragus lervia & Aoudad or Barbary sheep & 58 & - & Centromeres (d-f) \\
& Ovis aries & Domestic sheep & 54 & Ladder & Centromeres (g-i) \\
Aepycerotini & Aepyceros melampus & Impala & 60 & - & Minimal hybridization \\
\hline
\end{tabular}

$\begin{array}{llllll}1 & 2 & 3 & 4 & 5 & 6\end{array}$ $\begin{array}{llllll}1 & 2 & 3 & 4 & 5 & 6\end{array}$
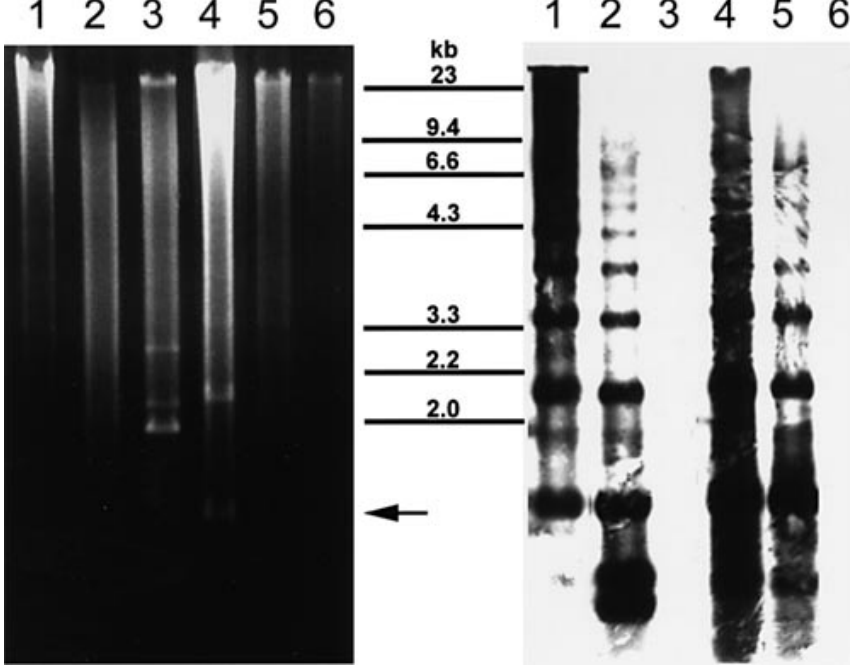

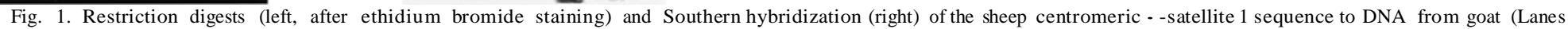

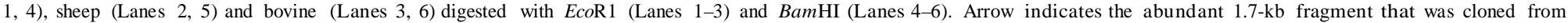
sheep. Alternate lanes from a single membrane and luminograph are shown. 

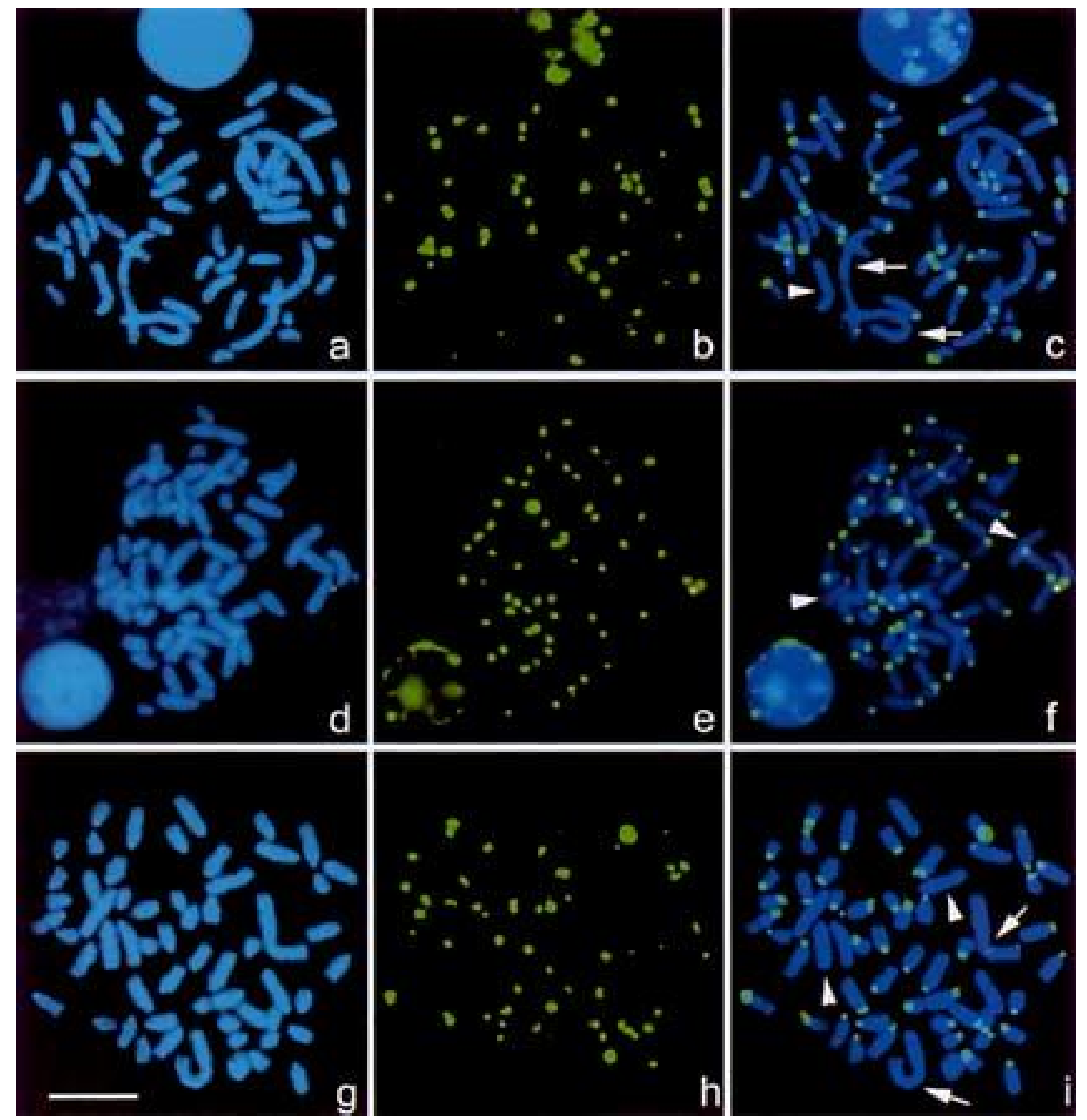

Fig. 2. In situ hybridization of the sheep centromeric - -satellite 1 sequence (green hybridization signal, centre and right pictures) to metaphase chromosomes (counterstained blue with DAPI, left, and shown with overlay of hybridization signal, right) of (a, b, c) sheep (male, $2 \mathrm{n}=54, \mathrm{XY}$ ), (d, e, f) goat (male, $2 \mathrm{n}=60, \mathrm{XY})$ and $(\mathrm{g}, \mathrm{h}, \mathrm{i})$ aoudad (female, $2 \mathrm{n}=$ 58, XX). Arrows: biarmed chromosomes essentially without the satellite sequence. Arrowheads: X chromosomes without the satellite sequence. Scale bar15 İm. 